\title{
A CASE OF CUSHING'S DISEASE EVALUATED BY INFERIOR PETROSAL SINUS SAMPLING - A NOVEL APPROACH IN BANGLADESH
}

\author{
PRASAD I ${ }^{1}$, ANSARI MAJ ${ }^{2}$, RAHMAN KM ${ }^{3}$, SAHA J ${ }^{4}$, HOSSAIN MZ ${ }^{5}$, TALUKDER DC ${ }^{6}$,
}

\begin{abstract}
:
A 16 years old boy presented to the Department of Endocrinology, Sir Salimullah Medical College \& Mitford Hospital with the complaints of occasional headache, vomiting and gradual weight gain for the last 5 years. He was overweight \& has moon face, lipomastia, striae over the abdomen. His random blood sugar was $15 \mathrm{mmol} / \mathrm{l}$, serum potassium was low, no suppression of serum cortisol on low dose $1 \mathrm{mg}$ dexamethasone suppression test (297 $\mathrm{nmol} / \mathrm{l}$ )(cut of $<140$ $\mathrm{nmol} / \mathrm{l}$ ), loss of diurnal rhythm of serum cortisol (morning $430 \mathrm{nmol} / \mathrm{l}$, midnight $992 \mathrm{nmol} / \mathrm{l}$ ), $24 \mathrm{~h}$ urinary free cortisol in the upper limit of normal $(164 \mathrm{mcg})$, modest elevation of serum adrenocorticotropic hormone $(A C T H)(59.7 \mathrm{pg} / \mathrm{ml})$, no significant gradient of serum ACTH level between internal jugular and femoral vein, normal adrenal glands on computed tomography (CT) abdomen, pituitary microadenoma on magnetic resonance imaging (MRI) of Sella. On above clinical examination and, investigation he was diagnosed as Cushing's disease with diabetes mellitus. This patient was referred to department of neurosurgery for surgical management. The patient is now on medical treatment. Ketoconazole for hypercortisolism, lifestyle modification and metformin for diabetes mellitus. He is expected to have the neurosurgical treatment shortly.
\end{abstract}

Key words: Cushing's syndrome; Cushing's disease.

J Dhaka Med Coll. 2013; 22(1) : 96-101.

\section{Introduction:}

Cushing's syndrome refers to the constellation of the clinical signs and symptoms due to longstanding glucocorticoid excess from any source. ${ }^{1}$ Cushing's disease one of the causes of this syndrome is caused by ACTH secreting pituitary tumors. Microadenomas are the most common cause in all ages. In general iatrogenic Cushing's syndromes are common. But in childhood and adolescence Cushing's disease accounts for $75-80 \%$ of pediatric Cushing's syndrome cases according to some reports. ${ }^{2}$ The main early clinical features in children are weight gain and growth failure. ${ }^{3-8}$ Other common features are moon face, plethora, acne, hirsutism, striae, hypertension, pubertal arrest and personality changes. ${ }^{3-8}$ The manifestations of personality changes in children have been reported variously in different literatures. ${ }^{3-6,9}$

Confirming the diagnosis of Cushing's disease is not always straightforward especially in children and adolescents. ${ }^{10}$ Variations in the clinical features, cyclical nature of hypercortisolism in some cases and subclinical cases imparts difficulties in diagnosis. Hypercortisolism is usually associated with the loss of normal circadian rhythm of cortisol secretion in addition to its usual clinical

1. Dr Indrajit Prasad, Assistant Professor, Department of Endocrinology, Sir Salimullah, Medical College \& Mitford Hospital, Dhaka.

2. Dr. M A Jalil Ansari, Professor \& Head, Department of Endocrinology, Sir Salimullah Medical College \& Mitford Hospital, Dhaka.

3. Dr. Kazi Mohibur Rahman, Assistant Professor, Department of Neurology, Dhaka Medical College \& Hospital, Dhaka.

4. Dr. Joysree Saha, Registrar, Department of Obstetrics \& Gynaecology, Popular Medical College Hospital, Dhaka.

5. Dr. Mohammad Zaid Hossain, Assistant Professor of Medicine, Dhaka Medical College Hospital. Dhaka.

6. Dr. Debesh Chandra Talukder, Assistant Professor, Department of ENT, Dhaka Medical College \& Hospital, Dhaka

Correspondence: Dr Indrajit Prasad, Assistant Professor, Department of Endocrinology, Sir Salimullah Medical College \& Mitford Hospital, Dhaka. Email: drindrajit1976@yahoo.com 
features. The localization of the sources of cortisol/ACTH secretion usually based on the imaging studies like CT scan, MRI and ultrasonography. In addition selective sampling of blood from the draining veins of the suspected organs for hormone assays are needed to locate the lesions. Dexamethasone suppression tests are successfully utilized to evaluate the hypothalamic pituitary adrenal axis since long. ${ }^{2-5,8,9,11-15}$ Microadenomas are usually very small and pituitary imaging may sometimes fail to detect the lesion. ${ }^{11,13}$ Early diagnosis and treatment of Cushing's disease in children may prevent short height in adult life and osteopenia. ${ }^{8,16,17}$ Transphenoidal pituitary adenomectomy is the treatment of choice in this children and a high cure rate has been reported. ${ }^{3-5,7-9,11}$

The success of surgical treatment depends on how selective is the removal of the tumor keeping the unaffected tissues intact. The selective removal of the adenomatous tissue needs precise location of the tumor. For diagnosis and identification of the site of the pituitary tumor inferior petrosal sinus sampling from both sides are used in many centers. The level of ACTH in these samples are compared with ACTH levels of systemic venous samples to determine the gradient and interpreted to diagnose and locate the side and site of the lesion. Internal jugular venous samples are also used instead of inferior petrosal samples in cases of difficulties reaching inferior vena cava or in congenital anomalies of the inferior petrosal sinus formations which are not uncommon. The utility of selective sampling from either location are unquestionable. In this article we report the details of clinical presentation, evaluation and management approach of an adolescent boy who was a case of Cushing's disease. We attempted bilateral simultaneous inferior petrosal sinus sampling and performed sampling from the internal jugular veins. To the best of our knowledge it is first of its kind that selective venous sampling from the inferior petrosal sinus/ internal jugular veins for the evaluation of Cushing's disease has been done in Bangladesh. We consider this report to be exciting and encouraging to stimulate further development and application of rare procedures in our country.

\section{Case report:}

A 16 years old boy from Manikgangj district was brought by his father to the Endocrinology out-patient department in April 2011 with the complaints of occasional headache, vomiting , gradual weight gain and weakness for the last 5 years. He also complained of recurrent skin infections and boils in deferent parts of the body for the same duration. He was treated by the local doctors by antibiotics, topical medications, and vitamins without satisfactory improvement. At presentation, he was overweight (BMI $28.7 \mathrm{~kg} / \mathrm{m}^{2}$ ) had moon face, bilateral enlarged breasts which was later found to be due to lipomastia, striae over the abdomen, normal blood pressure(115/ $75 \mathrm{mmHg}$ ), normal stretched penile length (9 $\mathrm{cm})$, normal testicular volume $(10 \mathrm{ml})$ and protruded abdomen. Examination of cardiovascular, respiratory, Gastrointestinal and neurological systems were normal. Routine examination of urine showed presence of reducing substance and others normal. Suspecting Cushing's syndrome he was admitted into the Endocrinology Department for evaluation. On laboratory investigation, random blood sugar was $15 \mathrm{mmol} / 1$ (normal upto $7.8 \mathrm{mmol} / 1$ ), serum potassium $3.8 \mathrm{mmol} /$ 1 (normal range 3.6 to $5.1 \mathrm{mmol} / 1$ ), CBC within normal range and morning serum cortisol 354 to $639 \mathrm{nmol} / 1$ as done on several occasions. Low dose (1mg) overnight dexamethasone

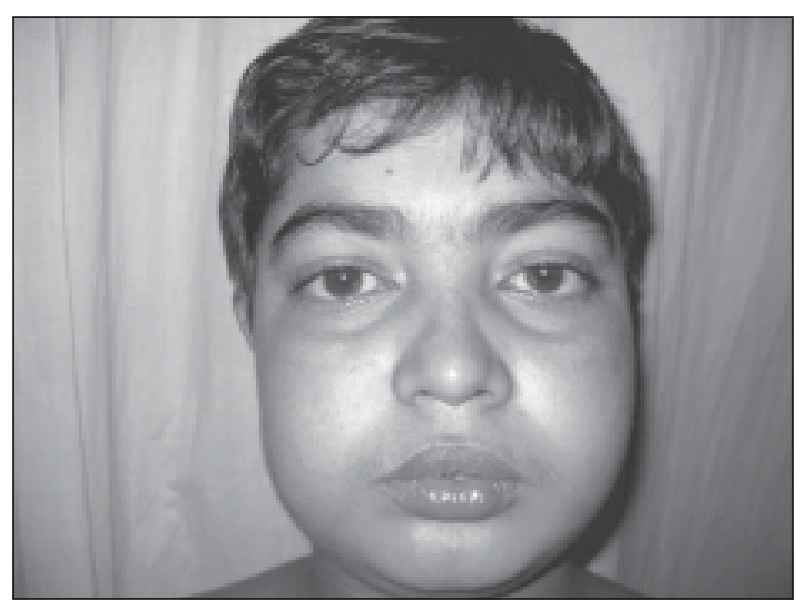

Fig.-1: Moon face of Cushing's disease 


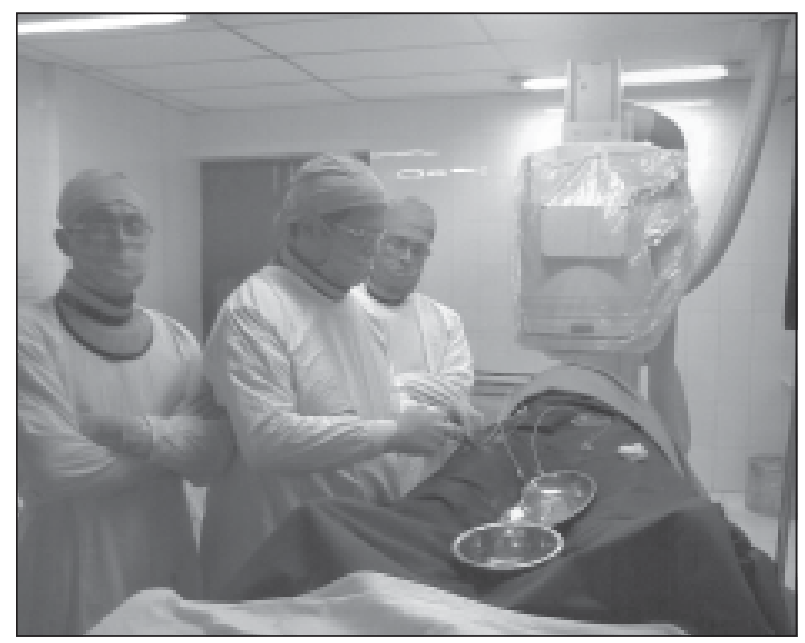

Fig.-2: Bilateral simultaneous inferior petrosal sinus sampling is underway.

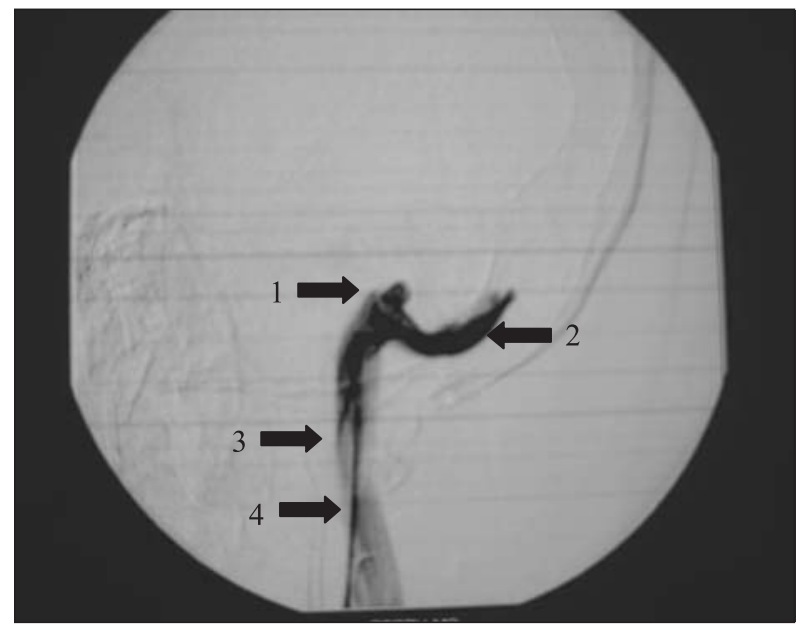

Fig.-3: Selective left venous angiogram at the level of jugular bulb: 1-left jugular bulb, 2-left transverse sinus, 3-internal jugular vein, 4-catheter

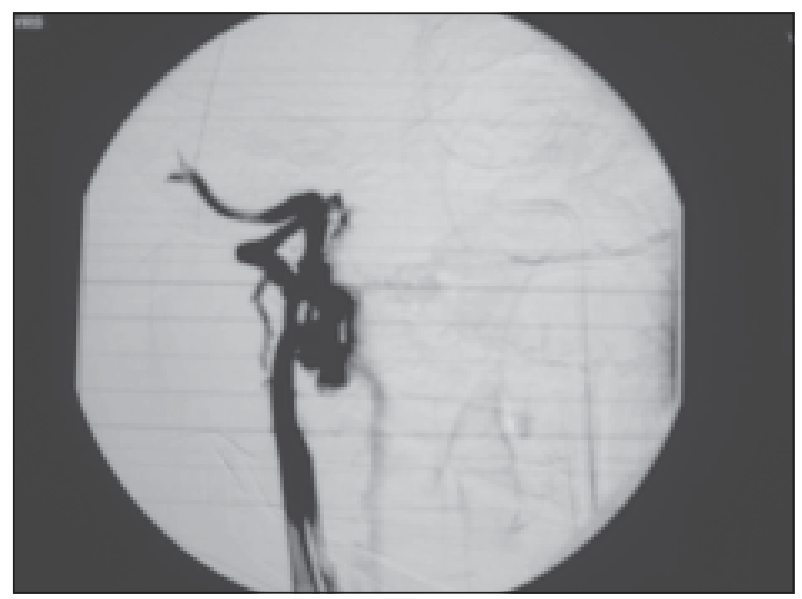

Fig.-4: Selective right venous angiogram at the level of jugular bulb: 1-right jugular bulb, 2-right transverse sinus, 3-right internal jugular vein, 4-catheter suppression test was done and suppression was not significant (morning serum cortisol following dexamethasone was $297 \mathrm{nmol} / 1$, where values $<140 \mathrm{nmol} / 1$ is considered normal suppression). To assess the diurnal rhythm of cortisol secretion morning and midnight serum cortisol was compared. Patient had midnight serum cortisol $992 \mathrm{nmol} / 1$ and morning serum cortisol $430 \mathrm{nmol} / 1$ both done on the same day. The patient had $24 \mathrm{~h}$ urinary

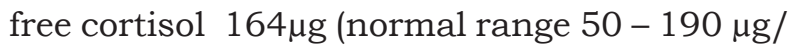
$24 \mathrm{hrs}$ ), serum ACTH $59.7 \mathrm{pg} / \mathrm{ml}$ (normal 8.3$57.8 \mathrm{pg} / \mathrm{ml}$ ), serum LH $2 \mathrm{mIU} / \mathrm{ml}$ ( Normal 2-8 $\mathrm{mIU} / \mathrm{ml}$ ), serum testosterone $6.8 \mathrm{ng} / \mathrm{ml}$ (normal 3-12 ng/ml), serum TSH $0.92 \mathrm{mIU} / \mathrm{L}$ (0.35-4.25mIU/L). From basal hypercortisolemia, lack of suppression by overnight dexamathasone suppression test, loss of diurnal rhythm of cortisol secretion, hyperglycemia and characteristic clinical features the patient was diagnosed as a case Cushing's disease though $24 \mathrm{~h}$ urinary free cortisol was in the upper limit of normal, serum ACTH was only modestly elevated and serum potassium was in the lower limit of normal range. To exclude ectopic or adrenal sources for hypercortisolemia CT scan, ultrasonography and plain radiological investigations were done. X-ray of skull, MRI and CT scan of the brain showed normal sized pituitary fossa with a pituitary microadenoma.

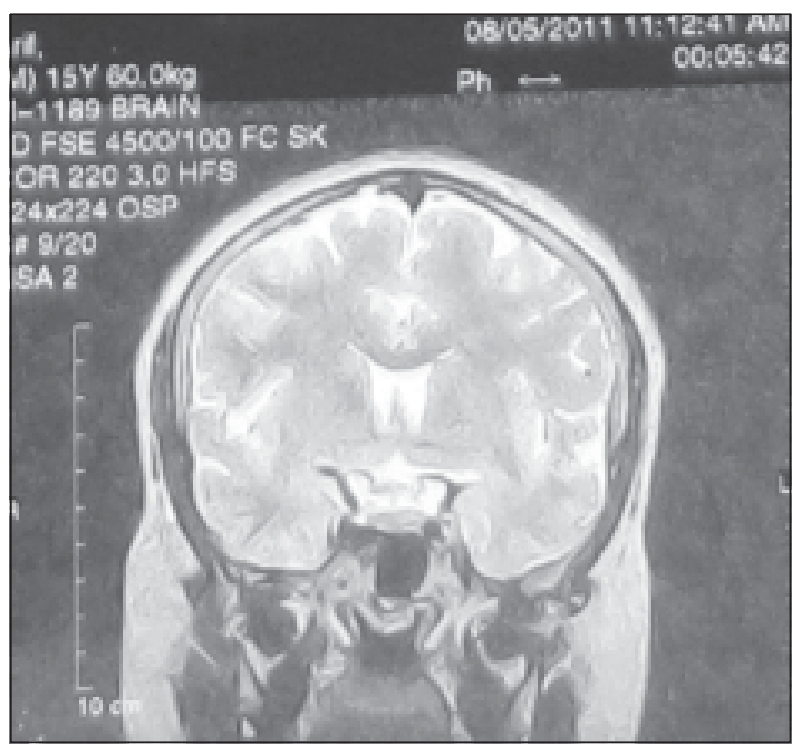

Fig.-5: Magnetic resonance imaging of head showing pituitary microadenoma (arrow). 
The patient was given the option for surgical treatment and in an attempt to localize the site of the lesion bilateral simultaneous inferior petrosal sinus sampling (BSIPSS) for ACTH estimation was done with the help of Department of Neurology, Dhaka Medical College Hospital, Dhaka, where interventional neuroimaging facilities were made available. We admitted the patient into Dhaka Medical College Hospital for this test and on 16/08/ 2011 this test was done. It was surprising to us and interventional neuroimaging specialist that this patient had anatomical anomalies of the inferior petrosal sinus the right inferior petrosal sinus being absent in this patient. Samples were taken from right and left internal jugular veins and from femoral veins for comparisons. No significant gradient of serum ACTH level was found between internal jugular and femoral vein samples. The internal jugular to femoral vein ACTH ratio was slightly more than 1 on the right side and very near to 1 in the left side. (Right internal jugular $63.9 \mathrm{pg} /$ $\mathrm{ml}$, Lt internal jugular $59.7 \mathrm{pg} / \mathrm{ml}$, femoral $59.1 \mathrm{pg} / \mathrm{ml}$ ). From these reports nothing could be added to our diagnosis. The patient was referred to neurosurgical department for surgical removal of pituitary adenoma, evaluated by the surgical team and waiting for transsphenoidal surgical removal of pituitary adenoma. By this time, he was on diet control and metformin $1000 \mathrm{mg} /$ day for diabetes mellitus and gradually increasing dose. Ketoconazole the latest being $600 \mathrm{mg} /$ day for hypercortisolism. He is under three monthly follow-up from Endocrinology OPD. He is compliant, gained $5 \mathrm{Kg}$ weight in the last 10 months and muscle weakness is still persisting as before. The basal serum cortisol levels on follow up visits were $560 \mathrm{nmol} / 1$ on $15 / 11 / 2011,649 \mathrm{nmol} / 1$ on $16 / 02 / 2012,786$ nmol/1 on $14 / 06 / 2012$ and 1012 on $13 / 09 /$ 2012. The glycemic control was good with fasting blood sugar within 4.9 to $6.2 \mathrm{mmol} / 1$ and $\mathrm{HbA}_{1} \mathrm{c}$ within $5.9 \%$ to $6.3 \%$ in different follow up visits until recently. As hypercortisolism continued to be raised the dose of ketoconazole was increased to observe the response. No significant complications from the medication were detected. He was expected to have the neurosurgical treatment shortly.

\section{Discussion:}

Cushing's disease is rare in children and its clinical presentation differs from those in adults. In children with Cushing's disease growth retardation may be an early and the most impressive sign. ${ }^{3-8}$ Other common presentation include obesity associated moon face, buffalo hump, bruising striae, hypertension and psychological disturbances. ${ }^{3-}$ 8 Our patient presented with occasional headache, vomiting and gradual weight gain. Clinical signs of hypercotisolaemia including hypertension and striae reported in a large series of patients from early childhood to late adolescents. ${ }^{3}$ Hypertension was not present in our case but there were pinkish srtiae over the abdomen. The diagnosis of Cushing's syndrome is based on clinical suspicion and biochemical confirmation of hypercortisolism. Abnormalities of diurnal variation of cortisol have been used for confirmation of Cushing's syndrome in several studies since first reported by Doe et al in $1960 .{ }^{18}$ Lack of diurnal rhythm in serum cortisol levels are the most sensitive index for hypercortisolism especially in children. 5,9,19,20 The patient in this report had high serum cortisol level at midnight which was almost double of the morning serum cortisol level. This indicates lack of normal diurnal rhythm. It has been reported that a single midnight plasma cortisol measurement can diagnose Cushing's syndrome. Cutoffs devised have varied from 48.6-202.5nmol/ $1 .{ }^{19,21}$ In our case the midnight serum cortisol was $992 \mathrm{nmol} / 1$. Batista et al also reported very high sensitivity (99\%) with $100 \%$ specificity using a midnight cortisol value of $118 \mathrm{nmol} /$ $1 .{ }^{22}$ Hypercortisolism cannot be suppressed by low dose dexamethason, our case supports this finding. Late night salivary cortisol is a new modality that could be a surrogate for midnight serum cortisol collection, but it requires assay standardization and determination of normal cutoff values for pediatric age group. Available studies report a sensitivity of $93 \%$ to $100 \%$ and specificity of $95 \%$ to $100 \%$ of late night salivary cortisol in pediatric age group. ${ }^{23,24}$ Basal and midnight ACTH identifies ACTH dependence with $100 \%$ sensitivity at cutoffs greater than $5 \mathrm{pg} / \mathrm{ml}$ and greater than $7.5 \mathrm{pg} / \mathrm{ml}$ respectively. 
In our case basal ACTH was $59.7 \mathrm{pg} / \mathrm{ml}$ which indicates ACTH dependence. Diabetes mellitus at presentation has been reported to be $15 \%$ in Cushing's disease. ${ }^{25}$ Our case had diabetes mellitus at presentation. After careful evaluation of above data pituitary imaging study should be arranged in patients with suspected Cushing's disease. Our patient showed pituitary microadenoma on MRI. One series showed 59\% detection rate of pituitary adenoma on MRI. ${ }^{26}$ Bilateral simultaneous inferior petrosal sinus sampling with or without corticotropin releasing hormone stimulation are recommended when lesions are hard to detect in imaging studies $.3,4,8,11,14,15$ In the attempt to do bilateral simultaneous inferior petrosal sinus sampling(BSIPSS) with the help of department of neurology, Dhaka Medical College Hospital we could reach up to high internal jugular vein (HJV) as because inferior petrosal sinus was congenitally absent on right side. No significant gradient of serum ACTH level was found between internal jugular and femoral vein (Rt internal jugular $63.9 \mathrm{pg} / \mathrm{ml}$, Lt internal jugular $59.7 \mathrm{pg} / \mathrm{ml}$, femoral $59.1 \mathrm{pg} /$ ml, HJV/Peripheral ACTH gradient was 1.08.In one series the Cushing's disease case who underwent HJV sampling had a peak central to peripheral ACTH ratio 0.95 even after corticotropin releasing hormone (CRH) stimulation. ${ }^{26}$

The patient is waiting for surgical treatment which will be done very soon. Transsphenoidal pituitary adenomectomy is the treatment of choice in patients with Cushing's disease. ${ }^{3-}$ 5,7-9,11 The signs and symptoms of hypercortisolism usually improve gradually within several months following surgery. The hypothalamic-pituitary-adrenal axis usually recovers in between 6 and 12 months , and substantial catch-up growth may occur. ${ }^{3}$ In patients who cannot be cured by first operation or who experience recurrence, repeated surgery or radiotherapy are considered as second-line treatments. ${ }^{4}$ Diabetes insipidus and hypopituitarism may develop after pituitary surgery or radiotherapy . ${ }^{4}$ Under such circumstances appropriate hormone replacement therapy is indicated. In patients with growth hormone deficiency, growth hormone therapy will be beneficial in terms of their adult height. ${ }^{8,14}$

In conclusion, weight gain and change in appearance being the most common presenting feature in children. A high index of suspicion is important in early and correct diagnosis of Cushing's disease.

\section{References:}

1. Cushing $\mathrm{H}$. The basophil adenomas of the pituitary body and their clinical manifestations (pituitary basophilism). Bull Johns Hopkins Hosp 1932; 50:137-5.

2. Magiakou MA \& Chrousos GP. Cushing's syndrome in children and adolescents: current diagnostic and therapeutic strategies. J Endocrinological Investigation 2002; 25: 181-4.

3. Magiakou MA, Mastorakos G, Oldfield EH, et al. Cushing's syndrome in children and adolescents: presentation, diagnosis, and therapy. N Engl J Med 1994; 331: 629-36.

4. Joshi SM, Hewitt RJ, Storr HL, et al. Cushing's disease in children and adolescents: 20 years of experience in a single neurosurgical center. Neurosurgery 2005; 57: 281-5.

5. Devoe DJ, Miller WL, Conte FA, et al. Long-term outcome in children and adolescents after transsphenoidal surgery for Cushing's disease. J Clin Endocrinol Metab 1997; 82: 3196-202.

6. McArthur RG, Cloutier MD, Hayles AB, Sprague RG. Cushing's disease in children: findings in 13 cases. Mayo Clin Proc 1972; 47: 318-26.

7. Kanter AS, Diallo AO, Jane JA Jr, et al. Singlecenter experience with pediatric Cushing's disease. J Neurosurg 2005; 103 (5): 413-20.

8. Sevage MO, Lienhardt A, Lebrethon MC, et al. Cushing's disease in childhood: presentation, investigation, treatment and long-term outcome. Horm Res 2001; 55 (1): 24-30.

9. Leinung MC, Zimmerman D. Cushing's disease in children. Endocrinol Metab Clin North Am 1994; 23: 629-39.

10. P.Y Hsy, Y.C. tung, C.T. Lee et al. Cushing's disease in Children: Report of three Cases. Pediatr Neonatol 2010; 51 (5): 303-7.

11. Storr HL, Afshar F, Matson M, et al. Factors influencing cure by transsphenoidal selective adenomectomy in pediatric Cushing's disease. Eur J Endocrinol 2005; 152: 825-33.

12. Liddle GW. Tests of Pituitary-adrenal suppressibility in the diagnosis of Cushing's syndrome. J Clin Endocrinol Metab 1960; 20:1539-60. 
13. Batista D, Courkoutsakis NA, Oldfield EH, et al. Detection of adrenocorticotropin-secreting pituitary adenomas by magnetic resonance imaging in children and adolescents with Cushing disease. J Clin Endocrinol Metab 2005: 90:513440 .

14. Batista D, Gennari M, Riar J, et al. Assessment of petrosal sunus sampling for localization of pituitary microadenomas in children with Cushing disease. J Clin Endocrinol Metab 2006; 91: 2214.

15. Lienhardt A, Grossman AB, Dacie JE, et al. Relative contributions of inferior petrosal sinus sampling and pituitary imaging in the investigation of children and adolescents with ACTH-dependent Cushing's syndrome. J Clin Endocrinol Metab 2001; 86: 5711-4.

16. Davies JH, Storr HL, Davies K, et al. Final adult height and body mass index after cure of pediatric Cushing's disease. Clin Endocrinol (Oxf) 2005; 62:466-72.

17. Di Somma C, Pivonello R, Loche S, et al. Effect of 2 years of cortisol normalization on the impaired bone mass and turn-over in adolescent and adult patients with Cushing's disease: a prospective study. Clin Endocrinol (Oxf) 2003; 58: 302-8.

18. Doe RP, Vennes JA, Flink EB. Diurnal variation of 17-hydroxycorticosteroids, sodium, potassium, magnesium and creatinine in normal subjects and in cases of treated adrenal insufficiency and Cushing's syndrome. Clin Endocrinol Metab 1960; 20: 253-65.
19. Newell-Price J, Trainer P, Perry L, Wass J, Grossman A, Besser M. A single sleeping midnight cortisol has $100 \%$ sensitivity for the diagnosis of Cushing's syndrome. Clin Endocrinol (Oxf) 1995;43:545-50.

20. JH Liu, RR Kazer, DD Rasmussen. Characterization of the twenty-four hour secretion patterns of adrenocorticotropin and cortisol in normal women and patients with Cushing's disease. J Clin Endocrinol Metab 1987; 64:102735 .

21. Trainer PJ, Grossman AB, The diagnosis and differential diagnosis of Cushing's syndrome. Clin Endocrinol (Oxf) 1991; 34:317-30.

22. Batista DL, Riar J, Keil M, Stratakis CA, Diagnostic tests for children who are referred for the investigation of Cushing syndrome. Pediatrics 2007; 120:e572-e586.

23. Martinelli CE Jr, Sader SL, Oliveira EB, Daneluzzi JC, Moreira AC. Salivary cortisol for screening of Cushing's syndrome in children. Clin Endocrinol (Oxf) 1999; 51: 67-71.

24. Gafni RI, Papanicolaou DA, Nieman LK. Nighttime salivary cortisol measurement as a simple, noninvasive, outpatient screening test for Cushing's syndrome in children and adolescent. J Pediatr 2000; 137: 30-35.

25. Nalini SS, Joe G, Shrikrishna VA et al. Cushing disease in children and adolescents: Twenty years experience in a tertiary care centre in India. Endocrine Pract 2011; 17(3): 369-76.

26. Dias RP, Kumazan A, Chan LF. Diagnosis, Management and Therapeutic outcome in Prepubertal Cushing's disease. Eur J Endocrinol 2010; 162: 603-9. 